\title{
Unilateral Stand-Alone Cage for the Treatment of Foraminal Stenosis in Patients with Degenerative Scoliosis. A Case Series of 20 Patients Mark P Arts* and Jasper FC Wolfs
}

Neurosurgeon, Department of Neurosurgery, Medical Center Haaglanden, VA The Hague, The Netherlands

\begin{abstract}
Object: Neuroforaminal stenosis has been documented frequently in patients with degenerative lumbar scoliosis. Pedicle screw fixation with posterior lumbar interbody fusion is usually performed although a debate has been started on the need for unilateral or bilateral screws, or interbody fusion only. Trabecular Metal is a porous tantalum biomaterial with good osteoconductive properties, which may be suitable for unilateral interbody fusion aiming at enlargement of neuroforamen.
\end{abstract}

Methods: From July 2011 until January 2013, 20 consecutive patients with degenerative scoliosis-related foraminal stenosis were treated with unilateral stand-alone Trabecular Metal cages (Zimmer TM 500) without additional pedicle screw fixation. All patients presented with leg pain, with or without low back pain. Patients underwent CT and MRI to confirm neuroforaminal stenosis on the concave side of the degenerative scoliosis. All patients were followed-up and examined at 2 months after surgery (follow-up moment 1). Long-term follow-up (moment 2; mean 36 months) was available of 17 patients; 2 patients died of unrelated disease and 1 patient was lost to follow-up. On both follow-up moments, neutral and dynamic flexion-extension images were documented. Based on these images, the position of the cage was determined and the Cobb's angle of the segmental scoliosis (angle between the cranial endplate of the upper vertebral body and the caudal endplate of the lower vertebral body) was measured. The clinical outcome was measured by the patients' global perceived recovery according to the 7-point Likert scale; "complete recovery" and "almost complete recovery" were determined as good results.

Results: Most of the patients were operated on L3L4 and L4L5 (70\%). The mean duration of surgery was $56 \pm 15$ minutes. Surgical complications occurred in 5 patients, namely cerebrospinal fluid leakage (4 patients) and nerve root injury ( 1 patient) with sensory deficit. Good outcome (Likert 1 or 2 ) was reported by 14 patients $(70 \%)$ on the shortterm follow-up (moment 1 ), and by 9 patients $(53 \%)$ on the long-term follow-up (moment 2). Whenever Likert 1-3 was dichotomized, $95 \%$ of the patients on the short-term and $83 \%$ of the patients on the long-term reported at least some benefit from the operation. The mean Cobb's angle improved significantly from $13.4 \pm 5.1^{\circ}$ pre-operatively, to $6.1 \pm$ $3.5^{\circ}$ at moment 1 , and $7.1 \pm 3.6^{\circ}$ at moment $2(P<0.001)$. On follow-up moment 1 and 2 , radiographic examination showed subsidence in 3 and 9 patients, respectively. Pseudarthrosis around the stand-alone cage was only seen at follow-up moment 2 in 3 patients.

Conclusions: Instrumented fusion with bilateral pedicle screw fixation and interbody fusion may not always be necessary in patients with scoliosis-related foraminal stenosis. Unilateral stand-alone TM cages could be an alternative strategy in a subgroup of patients leading to correction of Cobb's angle and improvement of symptoms in most cases. However, the long-term result is moderately satisfying and could be explained by the development of cage subsidence over time.

Keywords: Stand-alone cage; Scoliosis; Foraminal stenosis; Fusion; Trabecular metal

\section{Introduction}

Radicular leg pain is usually being caused by lumbar disc herniation. However, entrapment of the nerve root in the foramen has been reported frequently in patients with degenerative lumbar scoliosis $[1,2]$. Medial facetectomy with opening of the neuroforamen can be effective although patients may have persistent or recurrent leg pain due to deformity-related decrease of the disc height [2]. For this reason, bilateral pedicle screw fixation with posterior lumbar interbody fusion is usually preferred although it may result in excessive blood loss, nerve root injury, or screw malpositioning. With the introduction of minimally invasive surgery, a debate has been started on the need for unilateral or bilateral screws, or bilateral interbody fusion only [3]. Marchi et al. documented good results of minimally invasive lateral interbody fusion with polyetheretherketone (PEEK) in patients with degenerative spondylolisthesis, although elderly and women tended to develop severe subsidence [4]. Contrary to PEEK, Trabecular Metal (TM) is a porous tantalum biomaterial with structure similar to bone with better osteoconductive properties than other biomaterials [5]. Lequin et al. performed placement of bilateral stand-alone TM cages in patients with recurrent disc herniation and showed solid fusion without cage migration [6]. Recently, a randomised study by van de Kelft and van Goethem also documented stable constructs with bilateral TM stand-alone cages with or without additional pedicle screw fixation [7]. Because of the high resistance forces of TM cages with solid fusion, one might argue the possible effectiveness of unilateral stand-alone cages in patients with unilateral collapse of the intervertebral disc. In this case series, we present the results of 20 patients with degenerative scoliosisrelated foraminal stenosis who have been treated with unilateral standalone TM cages without additional pedicle screw fixation.

\section{Materials and Methods}

\section{Patients}

From July 2011 until January 2013, 20 consecutive patients

*Corresponding author: Mark P Arts, M.D., PhD., Neurosurgeon, Department of Neurosurgery, Medical Center Haaglanden, PO Box 432, 1512 VA The Hague, The Netherlands, Tel: +31-70-3302054; Fax:+31-70-3301667; E-mail: m.arts@mchaaglanden.nl

Received March 04, 2016; Accepted March 22, 2016; Published March 24, 2016

Citation: Arts MP, Wolfs JFC (2016) Unilateral Stand-Alone Cage for the Treatment of Foraminal Stenosis in Patients with Degenerative Scoliosis. A Case Series of 20 Patients. J Spine 5: 294. doi:10.4172/2165-7939.1000294

Copyright: $\odot 2016$ Arts MP, et al. This is an open-access article distributed under the terms of the Creative Commons Attribution License, which permits unrestricted use, distribution, and reproduction in any medium, provided the original author and source are credited. 
with a mean age of 67 years (range 49-81 years) were treated with unilateral stand-alone Trabecular Metal cages (Zimmer TM 500). All patients presented with unilateral radicular leg pain, with or without low back pain, according to the dermatome of the compressed nerve root. Eight patients (40\%) had previous surgery at the index level. All patients underwent CT and MRI to confirm neuroforaminal stenosis with segmental degenerative scoliosis due to collapse of the ipsilateral intervertebral disc. Baseline characteristics are shown in Table 1.

All patients were followed-up and examined at 2 months after surgery (follow-up moment 1 ). Long-term follow-up (moment 2; mean 36 months) was available of 17 patients; 2 patients died of unrelated disease and 1 patient was lost to follow-up. On both follow-up moments, neutral and dynamic flexion-extension images were documented. Based on these images, the position of the cage was determined and the Cobb's angle of the segmental scoliosis (angle between the cranial endplate of the upper vertebral body and the caudal endplate of the lower vertebral body) was measured. Also, presence of pseudarthrosis around the cage and subsidence of the cage was documented. The clinical outcome measures were visual analog scale (VAS) score of leg pain and low back pain $(0-100 \mathrm{~mm}$, with higher score indicating worse pain), and patients' global perceived recovery measured by the 7-point Likert scale; "complete recovery" and "almost complete recovery" were determined as good results.

\section{Surgical technique}

Under general anaesthesia, the patient was placed on a Wilson frame in prone position. Through a $5-7 \mathrm{~cm}$ incision, the paraspinal muscles were detached subperiostally and retracted laterally on both sides. The lateral recess was opened and a vertical hemilaminectomy was performed on the symptomatic side to expose the affected disc level. After opening the ipsilateral intervertebral disc with a knife, an osteotome was placed in the intervertebral disc space and turned 90 degrees to further open the disc space. Any loose disc fragments were removed and the endplates were cleared with a curette. The ipsilateral disc space was packed with autologous bone chips and the Zimmer TM cage (length $23 \mathrm{~mm}$ ) was placed in the intervertebral disc space while protecting the dura and nerve root. Adequate positioning of the stand-alone cage was confirmed by fluoroscopy. In order to optimise visualisation of the affected nerve root in its parapedicular course, the procedure was continued crosswise from the contralateral side to the ipsilateral side. In this way, the facet was undercut and complete

\begin{tabular}{|c|c|}
\hline & Patients (\%) \\
\hline Sex & $5(25)$ \\
\hline Female & $15(75)$ \\
\hline Mean age (years) & $67($ range 49-81) \\
\hline Smoking & $7(35)$ \\
\hline Symptoms & $20(100)$ \\
\hline Leg pain & $12(60)$ \\
\hline Back pain & $8(40)$ \\
\hline Previous surgery at index level & $1(5)$ \\
\hline Level & $3(15)$ \\
\hline L1L2 & $9(45)$ \\
\hline L2L3 & $7(35)$ \\
\hline L3L4 & $13(65)$ \\
\hline L4L5 & $7(35)$ \\
\hline Lateralisation & \\
\hline Left & \\
\hline Right & \\
\hline
\end{tabular}

Table 1: Baseline demographics.

\begin{tabular}{|c|c|}
\hline Mean duration of surgery in min. (range) & $56(35-80)$ \\
\hline Complications (\%) & $5(25)$ \\
\hline Dural tear & $4(20)$ \\
\hline Nerve root injury & $1(5)$ \\
\hline Length of hospital stay in days (range) & $2(1-5)$ \\
\hline Revision surgery (\%) & $2(10)$ \\
\hline Cage migration & $1(5)$ \\
\hline Osteoporotic fracture T11 & $1(5)$ \\
\hline
\end{tabular}

Table 2: Operative characteristics.

facetectomy was prevented. Any remaining nerve root compression was treated by opening the neuroforamen distally towards the retroperitoneal space.

\section{Statistical analyses}

Student $\mathrm{t}$-tests were used to analyse all continuous variables, such as the Cobb's angle, and Chi-square test was used for all categorical variables. Results are presented as the means $+/$ - the standard deviations. $\mathrm{P}$ values less than 0.05 were considered to be statistically significant. Statistical analyses were carried out using SPSS version 20.

\section{Results}

\section{Surgical data}

All surgeries were performed by the 2 authors. Most of the patients were operated on L3L4 and L4L5 (80\%), and in 65\% of the patients the stand-alone cage was placed on the left side. The mean duration of surgery was 56 minutes (range 35-80 minutes). Surgical complications occurred in 5 patients, namely cerebrospinal fluid leakage (4 patients) and nerve root injury (1 patient) with sensory deficit. Three of these 5 patients had previous surgery at the index level. The mean hospital admission was 2 days (range 1-5 days) (Table 2).

\section{Clinical and radiological data}

Good outcome (Likert 1 or 2) was reported by 14 patients (70\%) on the short-term follow-up (moment 1), and by 9 patients (53\%) on the long-term follow-up (moment 2). Whenever Likert 1-3 was dichotomized, $95 \%$ of the patients on the short-term and $83 \%$ of the patients on the longterm reported at least some benefit from the operation. The mean $( \pm$ standard deviation) VAS leg pain and low back pain on moment 2 was 33 $\pm 34 \mathrm{~mm}$ and $41 \pm 35 \mathrm{~mm}$, respectively. The mean Cobb's angle improved significantly from $13.4 \pm 5.1^{\circ}$ pre-operatively, to $6.1 \pm 3.5^{\circ}$ at moment 1 , and $7.1 \pm 3.6^{\circ}$ at moment $2(\mathrm{P}<0.001)$ (Figure 1$)$. On follow-up moment 1 and 2, radiographic examination showed subsidence in 3 and 9 patients, respectively. Pseudarthrosis around the stand-alone cage was only seen at follow-up moment 2 in 3 patients (Figure 2). Radiological data is presented in Table 3.

During the follow-up period, 2 patients were re-operated; 1 patient with a history of rheumatoid arthritis, underwent pedicle screw fixation with bilateral interbody fusion because of cage migration with persistent leg pain; 1 patient with a history of Parkinson's disease, developed an osteoporotic fracture two levels above the affected segment which required vertebroplasty and a long segment pedicle screw fixation.

\section{Discussion}

Patients with degenerative scoliosis frequently present with radicular leg pain due to deformity-related segmental foraminal stenosis on the concave side of the curve $[1,2]$. These patients are usually treated with instrumented fusion aiming at decompression of the nerve root by enlargement of the neuroforamen and correction of the scoliosis. However, surgical treatment of degenerative scoliosis with 
Citation: Arts MP, Wolfs JFC (2016) Unilateral Stand-Alone Cage for the Treatment of Foraminal Stenosis in Patients with Degenerative Scoliosis. A Case Series of 20 Patients. J Spine 5: 294. doi:10.4172/2165-7939.1000294

Page 3 of 4

multilevel pedicle screw fixation may be associated with complications like excessive blood loss, malposition of screws, or neurological deficit, which could be prevented by treating patients with less invasive surgery. In the present study, we found that instrumented fusion with bilateral pedicle screw fixation and interbody fusion may not always be necessary to achieve improvement of symptoms.

The presented case series is not the first publication on stand-alone

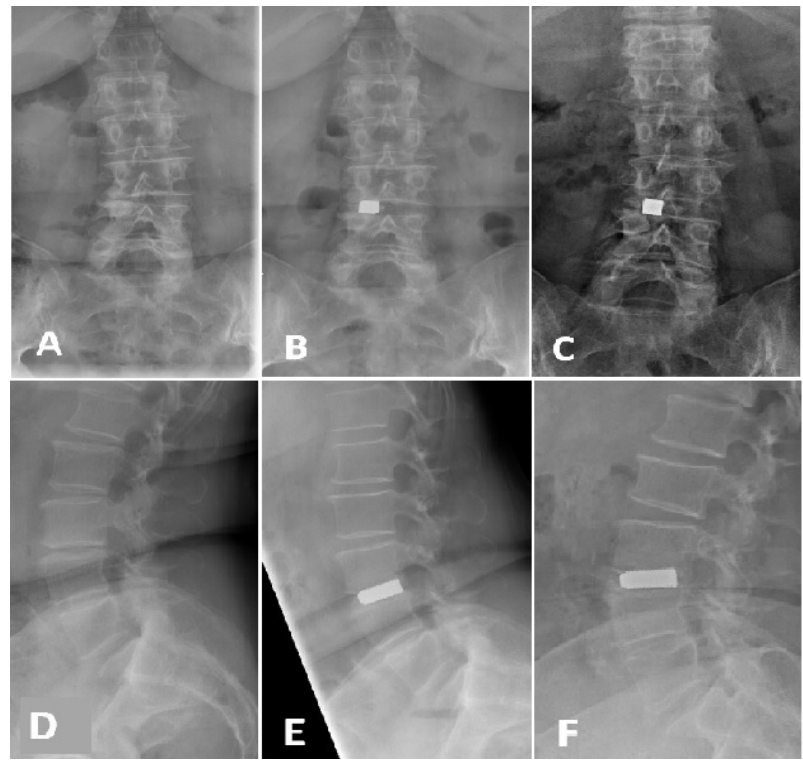

Figure 1: AP and lateral radiographs of a scoliosis-related foraminal stenosis L3 on the right side. Cobb's angle improved significantly from $10^{\circ}$ pre-operatively (A), to $4^{\circ}$ on follow-up moment 1 ( 2 months after surgery) (B), and $5^{\circ}$ on follow-up moment 2 (31 months after surgery) (C). Lateral X-ray showed enlargement of the disc height on both follow-up moments ( $E$ and $F$ ) compared to preoperative (D). On the last follow-up moment, Cobb's angle has increased slightly although the patient had no symptoms.

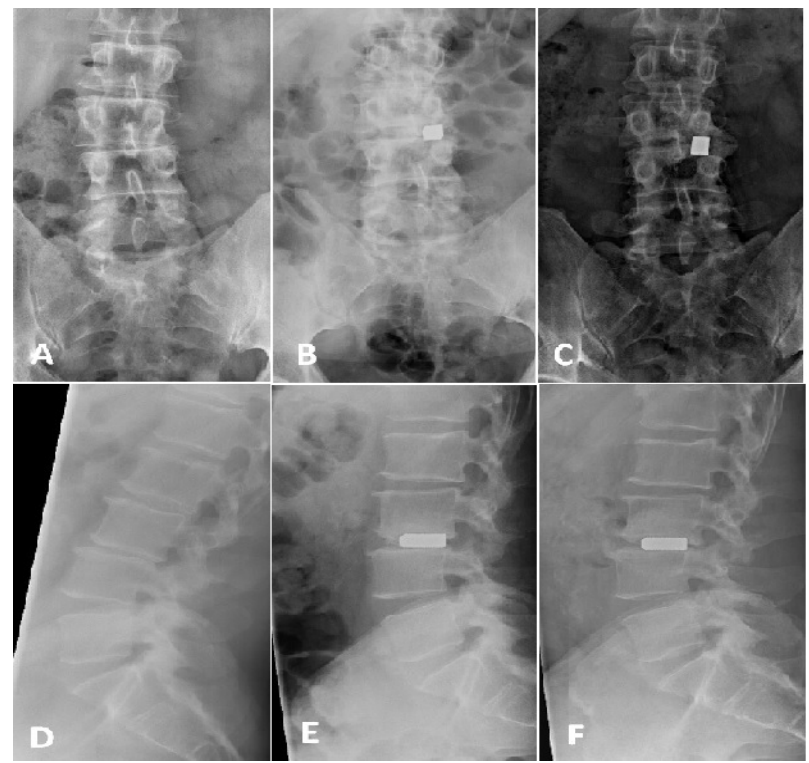

Figure 2: AP and lateral radiographs of a scoliosis-related foraminal stenosis L3 on the left side. Cobb's angle increased significantly from $10^{\circ}$ pre-operatively $(A)$ to $1^{\circ}$ degree on follow-up moment 1 (2 months after surgery) (B), and worsened to $4^{\circ}$ on follow-up moment 2 ( 41 months after surgery) (C). The loss of correction is caused by $3 \mathrm{~mm}$ subsidence of the stand-alone TM cage at follow-up moment 2 ( $\mathrm{C}$ and $\mathrm{F})$.

\begin{tabular}{|c|c|c|c|}
\hline & Pre-operative & Post-operative FU 1 & Post-operative FU 2 \\
\hline Cobb's angle $\left(^{\circ}\right)$ & $13.4 \pm 5.1$ & $6.1 \pm 3.5$ & $7.1 \pm 3.6$ \\
\hline Subsidence & NA & & \\
\hline $0 \mathrm{~mm}$ & & 17 & 5 \\
\hline $1 \mathrm{~mm}$ & & 1 & 2 \\
\hline $2 \mathrm{~mm}$ & & 2 & 5 \\
\hline $3 \mathrm{~mm}$ or more & & 0 & 2 \\
\hline missing & & 0 & 3 \\
\hline Pseudarthrosis & NA & 0 & 3 \\
\hline
\end{tabular}

Table 3: Radiological data on Cobb's angle, subsidence and presence of pseudarthrosis. Cobb's angle is measured by the angle between the cranial endplate of the upper vertebral body, and the caudal endplate of the caudal vertebral body. $\mathrm{NA}=$ not applicable.

cages. Park et al. reported 34 patients with foraminal stenosis treated with bilateral stand-alone expandable cages and $91 \%$ of the patients were satisfied [8]. The fusion rate was $88 \%$ and $30 \%$ of the patients were noted with subsidence, of which the majority had no symptoms. Park et al. also reported on long-term outcome of 211 patients with degenerative spine diseases treated with bilateral stand-alone expandable cages [9]. Five years after surgery, the overall clinical success rate dropped to $74.4 \%$. The fusion rate was $85.2 \%$ and the disc height was continuously reduced in time with poor sagital alignment. They concluded that, in particular in patients with multilevel surgery and high-risk pseudarthrosis such as diabetes, stand-alone intercorporal cages should not be used. Lequin et al. reported on bilateral standalone TM cages in patients with recurrent disc herniation [6]. Only $46 \%$ of the patients reported good outcome although $85 \%$ had some benefit from the operation. However, $69 \%$ of the patients had a history of 2 or more surgeries on the index level, which could explain the modest results. Recently, van der Kelft and van Goethem published a randomised trial on 80 patients treated with bilateral TM cages, with or without additional pedicle screw fixation [7]. There was no difference in clinical and radiological outcome between both groups and TM cage were shown to provide solid constructs, irrespective of additional pedicle screw fixation.

The radiographic examination on both short and long term followup clearly show a significant correction of the segmental scoliosis by placement of unilateral stand-alone TM cages on the concave side of the curve. Cobb's angle of the affected level improved from approximately $13^{\circ}$ pre-operatively to $6-7^{\circ}$ post-operatively. However, during followup, subsidence of the cage may occur with consequent decrease of the disc height and neuroforamen. This may explain worse outcome on long-term follow-up compared to the short-term follow-up.

In our study, $70 \%$ of the patients reported good outcome on the short-term which dropped to $53 \%$ on the long-term. This long-term moderately satisfying result has also been documented by Lequin et al [6]. Since $40 \%$ of our patients have been operated before at the index level, could mean that some of the patients presented with failed back surgery syndrome, which is associated with poor surgical outcome [10]. Another explanation of poor long-term results could be the subsidence of the stand-alone cage with consequent decrease of disc height, which occurred in 9 patients to some extent.

The surgical procedure of unilateral stand-alone cages has some advantages compared to bilateral interbody fusion with pedicle screw fixation; the technique is straightforward and less time-consuming, the implant cost is lower, and pedicle screw-related complications are avoided. However, there are also some disadvantages. The complication rate of nerve root injury and dural tear is relatively high, which could be explained by the fact that some procedures include revision surgery with associated peridural fibrosis. The rough surface of the TM cage 
may also result in dural tear when the surgical corridor is less widely exposed as in medial facetectomy in cases with additional pedicle screw fixation.

During the follow-up period, 2 patients were re-operated and both patients had poor bone quality related to rheumatoid arthritis in one patient and osteoporosis in the other patient. Therefore, in our opinion, stand-alone TM cages should not be performed in patients with poor bone quality, in patients with high risk of pseudarthrosis like diabetes mellitus, or in patients with spondylolisthesis. For biomechanical reasons, a unilateral stand-alone cage should only be inserted in a single level.

In conclusion, the described technique of unilateral stand-alone TM cages could be an alternative in a selection of patients with degenerative scoliosis-related foraminal stenosis. Cobb's angle will improve significantly and most patients will benefit to some extent. However, the long-term result is moderately satisfying which could be explained by the development of cage subsidence over time.

\section{Disclosure}

The authors report no conflict of interest concerning the materials or methods used in this study.

\section{References}

1. Jenis LG, An HS, Gordin R (2001) Foraminal stenosis of the lumbar spine: a review of 65 surgical cases. Am J Orthop (Belle Mead NJ) 30: 205-211.

2. Yamada K, Matsuda H, Nabeta M, Habunaga H, Suzuki A, et al. (2011) Clinical outcomes of microscopic decompression for degenerative lumbar foraminal stenosis: a comparison between patients with and without degenerative lumbar scoliosis. Eur Spine J 20: 947-953.

3. Aoki Y, Yamagata M, Ikeda Y, Nakajima F, Ohtori S, et al. (2012) A prospective randomized controlled study comparing transforaminal lumbar interbody fusion techniques for degenerative spondylolisthesis: unilateral pedicle screw and 1 cage versus bilateral pedicle screws and 2 cages. J Neurosurg Spine 17: 153159 .

4. Marchi L, Abdala N, Oliveira L, Amaral R, Coutinho E, et al. (2012) Standalone lateral interbody fusion for the treatment of low-grade degenerative spondylolisthesis. ScientificWorldJournal: 456346.

5. Sinclair SK, Konz GJ, Dawson JM, Epperson RT, Bloebaum RD (2012) Host bone response to polyetheretherketone versus porous tantalum implants for cervical spinal fusion in a goat model. Spine (Phila Pa 1976) 37: E571-580.

6. Lequin MB, Verbaan D, Bouma GJ (2014) Posterior lumbar interbody fusion with stand-alone Trabecular Metal cages for repeatedly recurrent lumbar disc herniation and back pain. J Neurosurg Spine 20: 617-622.

7. Van de Kelft E, Van Goethem J (2015) Trabecular metal spacers as standalone or with pedicle screw augmentation, in posterior lumbar interbody fusion: a prospective, randomized controlled trial. Eur Spine J 24: 2597-2606.

8. Park JH, Bae CW, Jeon SR, Rhim SC, Kim CJ, et al. (2010) Clinical and radiological outcomes of unilateral facetectomy and interbody fusion using expandable cages for lumbosacral foraminal stenosis. J Korean Neurosurg Soc 48: 496-500

9. Park JH, Roh SW (2011) Long-term clinical and radiological outcomes following stand-alone PLIF surgery using expandable cylindrical threaded cages in patients with degenerative lumbar spine disease. Acta Neurochir (Wien) 153: 1409-1416.

10. Arts MP, Kols NI, Onderwater SM, Peul WC (2012) Clinical outcome of instrumented fusion for the treatment of failed back surgery syndrome: a case series of 100 patients. Acta Neurochir (Wien) 154: 1213-1217. 